The International Journal of Multimedia \& Its Applications (IJMA) Vol.8, No.6, December 2016

\title{
Designing A Working Memory Capacity Test For Cognitive-FriENDLY TANGIBLE MULTIMEDiA
}

\author{
Chau Kien Tsong ${ }^{1}$, Zarina Samsudin ${ }^{2}$ and Wan Ahmad Jaafar Wan Yahaya ${ }^{3}$ \\ ${ }^{1}$ Faculty of Art and Design, Southern University College, Jalan Selatan Utama, \\ Off Jalan Skudai, 81300 Skudai, Johor, Malaysia \\ ${ }^{2,3}$ Centre for Instructional Technology and Multimedia, Universiti Sains Malaysia, \\ 11800 USM, Pulau Pinang, Malaysia
}

\begin{abstract}
A working memory capacity (WMC) test called "objects-span tri-tasks" is designed for preschoolers undergoing treatment using a new genre of multimedia, tangible multimedia, created by the authors. It tests the dual-functions of the preschoolers' working memory (WM), namely storage and manipulation capacity, essential in supporting academic skills. The third task in the test is the overt setting of task engaging the long-term memory that supports the operation of WM. Tangible multimedia potentially enhances the WMC of preschoolers to a considerable extent because firstly, it uses tangible objects that are cognitively appropriate to the "preoperational" stage of preschoolers, and secondly, it simultaneously stimulates three main sensory channels, prescribed as equally crucial in knowledge acquisition in human memory theories. A pragmatic significance of the research is that it deepens the scope of multimedia research by looking into the aspect of cognitive structure which is rarely conducted in the multimedia realm. It also demonstrates an important step forward in multimedia research by relating WMC to the newly explored tangible multimedia, which could determine the real capability and value of such system. This paper starts off by discussing the underlying theories that contribute to the formation of the system and test, followed by its procedure, and a brief report of a case study.
\end{abstract}

\section{KEYWORDS}

Dual-tasks; multimedia; preschoolers; tangible multimedia; tangible object; working memory capacity

\section{INTRODUCTION}

Working memory (WM) is an essential factor in supporting academic learning among students [1]. Correlational research works reveal a close relationship between WM and academic learning performance in writing [2], reading [3], science [4][5], Mathematics [6] [7], vocabulary knowledge [8][9] and English learning as a second language learning for adults [10] and early year children [11][12].

In view of the importance of WM to academic performance, there is a great need to create a multimedia system that could enhance the WM capacity (WMC) of learners. Close scrutiny reveals that previous multimedia research associated with cognitive functioning has mainly focused on memory retention [13][14]. Minimal attention has been given to the attributes that adapt and are cognitive-friendly to preschoolers' mental models. In conventional multimedia systems, information inputs for learning are often solely dependent on visual and auditory sensory channels. For preschoolers whose cognitive structures are preoperational as signified by Piaget [15][16], with unskilled motor acuity and limited vocabulary mastery [17], the sole use of visual and auditory attributes in multimedia is apparently insufficient.

DOI : $10.5121 /$ ijma.2016.8602 
There is also a dearth of research interest given to the possibility of multimedia playing a role in WM performance. Londe's [10] research demonstrates that WMC can be greatly improved [18]. Hence, designing a cognitive-friendly multimedia system which takes into account a preschooler's WM has the potential to improve both their short- and long-term academic achievement.

To develop a multimedia system that could enhance WMC, or is cognitive-friendly to preschoolers, one possible way is to design the system in accordance with the theoretical frameworks prescribed by Atkinson and Shiffrin's [19] human memory and Kieras and Meyer's [20] EPIC theories. These theories have one commonality, which is the need to engage tactile sensory channels in knowledge acquisition. By embracing the attribute that stimulates the tactile senses as part of instructional medium, preschoolers could learn naturally and tangibly. However, the question now is, how could we manifest the tactile attribute in digital multimedia? Considering the tactile and spatial characteristics that a tangible object possesses over other means of instruction, we are of the opinion that tangible objects serve as an excellent means to demonstrate tangibility in digital multimedia.

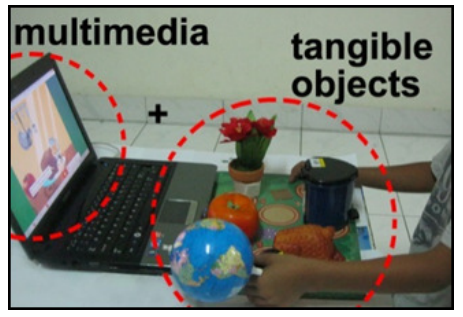

Figure 1. Tangible Multimedia: Adding Tangible Objects to Multimedia

There is a plethora of advantages in using tangible objects, which justifies the use of tangible objects in multimedia learning. A tangible object denotes an intuitive and natural way of learning [21]. Klemmer, Hartmann, and Takayama [22] pointed out that, "a natural place to start is with our hands, as they are simultaneously a means for complex expression and sensation ..." (p. 143). If hands are prevented from learning, various cognitive operations such as spatial working memory and lexical retrieval will be degraded [23]. Hands are crucial for children in learning [22]. Children learn through hands as natural motor response in human's daily life. Similar to toddlers, they like to touch things, and without realising, they learn, especially when they are engaged with concrete activities meaningful to them [24].

In defining concrete activities, Zuckerman and Resnick [25] asked, "How do we "concretise the abstract'? A physical, tangible interface can help. Children can touch it, can tinker with it ....." (p. 811). Manches [26] is of the opinion that "concrete" is in the sense of being connected with perceptual experience. Maria Montessori acknowledges the role of physical objects in the children's mind. She said, "Children build their mental image of the world, through the action and motor responses; and, with physical handling, they become conscious of reality" [27][28]. Ample literature can be cited in support of the tangible objects [29][30][31]. Thus, we have a cogent reason to believe that tangible objects enhance the operation of WM of preschoolers.

Augmented with tangible objects, multimedia learning can also be used to maximise learning performance and at the same time, lessen the amount of cognitive efforts in WM. Based on the idea of load sharing in cognitive load and dual-coding theories [32][33], additional tactile sensory could offload the burden of cognitive operation [29][26]. This is because the processing load is spread over three sensory channels of learners, thereby leaving a larger portion of memory space in each channel for learning. Oh [34] stated that simultaneous processing of information using the 
two channels results in an additive effect on learning. In our opinion, the engagement of additional tactile channel completes the set of additive effects.

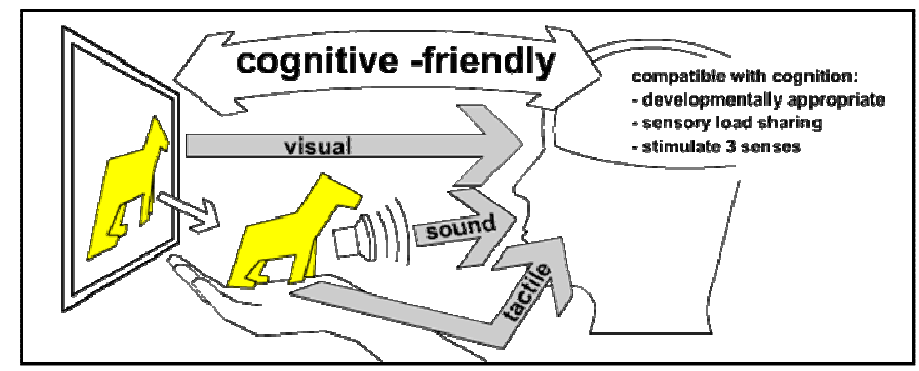

Figure 2. Tangible Multimedia: Cognitive-Friendly Multimedia for Preschoolers

As advantages of embracing tangible objects are abundant, a "new breed" of multimedia, that is a multimedia augmented with tangible objects, is hereby proposed. As it capitalises on the tangibility nature of physical objects, we propose to term it as "tangible multimedia". As a newly explored area, we have problem to determine the structure of a tangible multimedia system. We are concerned about the way the tangible objects should be used, the criteria to qualify a system as a tangible multimedia, and the relationship between tangible objects and multimedia objects. Therefore, a relevant framework that outlines the basic structure of tangible multimedia is conceived in the following section as grounding guidelines and reference.

\section{Proposing Theoretical Framework For Defining Tangible MULTIMEDIA}

Tangible multimedia is a genre of multimedia learning system that is augmented with tangible objects for preschoolers.

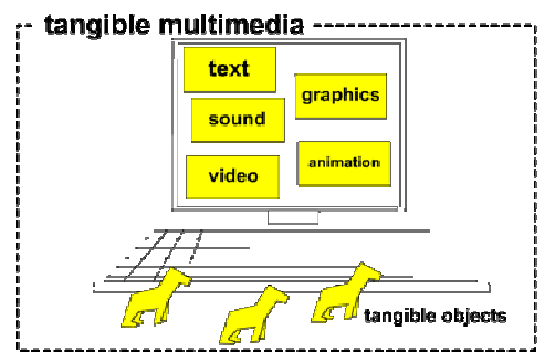

Figure 3. Taxonomy of Tangible Multimedia

The framework for tangible multimedia proposes taxonomy of tangible multimedia is to be defined as the combination of six multimedia objects, namely graphic, animation, text, audio, video and tangible objects. Tangible object is delineated as an independent component of multimedia objects. It serves as a means to manifest the sense of tangibility in multimedia useful for preschool learning. Via tangible objects, multimedia objects are "externalised" from digital world to physical space; thereby give young preschoolers a kind of illusion that they gain the experience of "tangibility" in multimedia context. 
The International Journal of Multimedia \& Its Applications (IJMA) Vol.8, No.6, December 2016

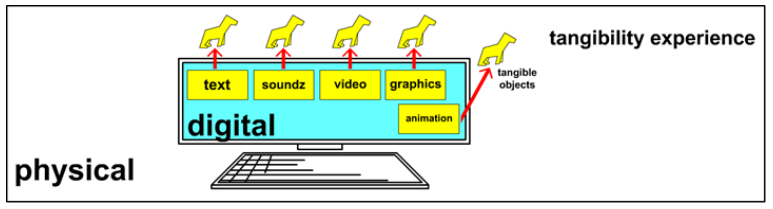

Figure 4. Externalisation of Multimedia Objects via Tangible Objects

Digital multimedia should be well-integrated, and only displayed through a single computer screen [35]. Conforming to this characteristic, our tangible multimedia framework proposes that all components in tangible multimedia should also be delivered in a way that they are unified meaningfully, and designed as an integrated entity whereby each of the multimedia objects is treated equally important and complement each other in a concordant manner to realise the allaround tangibility for preschoolers learning. If tangible objects are isolated from the whole system, the research would likely turn out to be a TUI research [29][36], rather than research of tangibility in multimedia context. The same manner is applied on the case study where the effects on preschoolers would be attributed to the contribution of all the components in tangible multimedia, not solely tactile component.

At the outset, tangible multimedia compliant with the proposed framework exposes limitations that may affect its efficacy. One of the limitations is that tangible objects add complexity to the system in the view of preschoolers. To overcome this limitation, we propose learning theories, namely Constructivist and Cognitivist theories, and multimedia design principles, Mayer's cognitive theory of multimedia learning to be part of the framework (Figure 5).

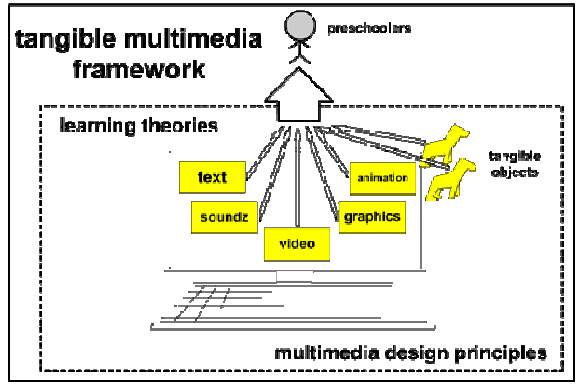

Figure 5. Learning Theories and Multimedia Design as Part of the Framework

The adaptation of tangible objects into genuine multimedia learning for preschoolers remained absent. Although there were abundant research works, such as Tangible User Interface [37] that utilised tangible objects, they are not rightfully tangible multimedia because they deemphasise the role of learning theories and multimedia design principles and loosely associate tangible objects with digital multimedia objects. They even could discard the entire multimedia objects in their system. Their target is more on how tangible objects can be utilised to facilitate human-computer interaction [38][39]. For them, multimedia objects are purely testing elements deployed for assessing the usability of tangible objects designated as a natural form of interaction interface.

\section{CONTRIBUting Theories For WMC TeSt AND TANgible MUltimedia}

To explore the potential of tangible multimedia, a case study had been conducted. During the course of the case study, we encountered great difficulty in locating a testing instrument of similar domain. Because of this, we designed a WM testing instrument called "objects-span tritasks" test. This section provides succinct discussion on the underlying theories that form the basis of the "objects-span tri-tasks" test and tangible multimedia. 
The International Journal of Multimedia \& Its Applications (IJMA) Vol.8, No.6, December 2016

\subsection{AtKinson And SHIFFrin's Human MEMORY THEORY (ASHM)}

ASHM was the first theory to postulate the existence of tactile sensory channel in the process of information acquisition. Accordingly, the information (stimuli inputs) is best learned if it is registered in visual, auditory and haptic sensory stores simultaneously before they are passed onto short-term store (STS), a pure temporary storage platform in human brain. Information in STS will decay with time quickly [40][41], hence, a continuous rehearsal is required for it to be transferred to long-term store (LTS) for permanent storage (Figure 6).

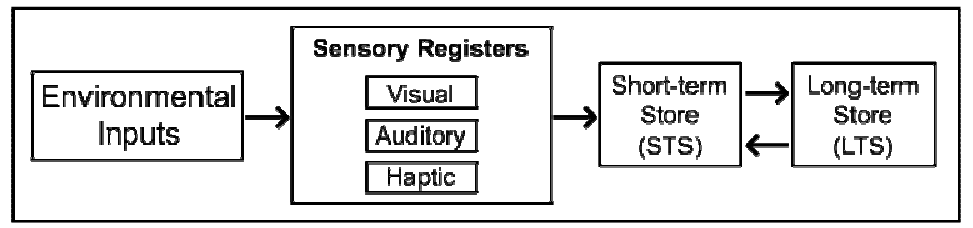

Figure 6. ASHM (Simplified And Adapted From [19] [41] )

Interaction between STS and LTS is bidirectional. During the period where information resides in STS, relevant information in LTS will be activated, retrieved, and subsequently placed in STS. ASHM's account of STS and LTS does not require that the two stores must be in different parts of the brain, or that they must involve different physiological structures [41].

\subsection{Kieras AND Meyer's Executive Process-Interactive Control FRAMEWORK (EPIC)}

EPIC is by far the most comprehensive WM model elaborated on tactile sensory channel in human cognition. EPIC explicates that human cognitive structure consists of a central cognitive processor (WM and long-term memory) surrounded by many peripheral perceptual processors (visual, auditory, and tactile) and motor processors (vocal, manual and ocular-motor (eye)).

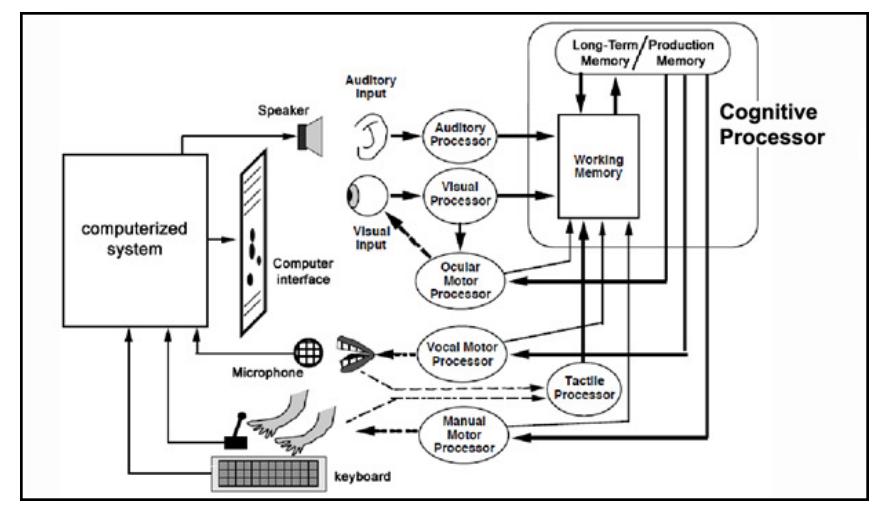

Figure 7. EPIC Framework (Adapted From [42])

The information processing starts from perceptual processors where the visual, auditory and tactile processors accept information from sense organs (hand, eyes, vocal). The information is then deposited into WM in cognitive processor. As a response to the receipt of information, WM yields multiple commands to motor processors to trigger overt movement of relevant sense organs. At the end of the process, the motor processors may generate feedback for WM. 


\subsection{BADDELEY's WORKING MEMORY THEORY (BWM)}

BWM posits that WM is not only a brain system functions as a temporary memory storage, but also a mental blackboard for information processing [43]. In other words, WM is a platform for dual-functionality of cognitive processes, where information held in short-term memory is operated and manipulated (processing function) simultaneously. Unlike ASHM and EPIC, BWM does not perceive the tactile modality as sensory channels played role in information acquisition. It asserts that humans only possess two distinct channels, phonological loop (represents verbal information) and visuo-spatial sketchpad (represents pictorial and spatial information) that is managed by a supervisory system named "central executive". BWM tradition adopts the belief that tactile stimuli are logged through the visual sensory channel [44].

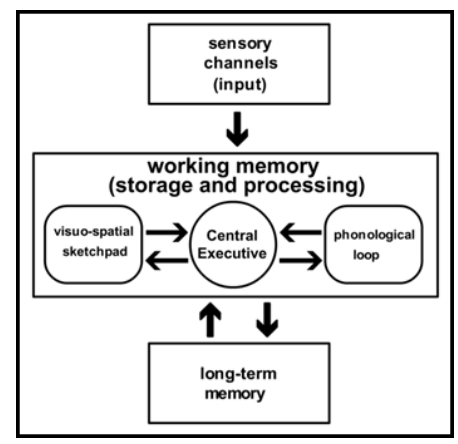

Figure 8. Subcomponents of WM [43]

In BWM, WM and long-term memory (LTM) are structurally separated. However, similar to ASHM, they are not perceived to be operated in isolation, but instead highly dependent on each other. To account for processing large amounts of information, such as comprehending a sentence, WM is extended to include LTM so that contextual knowledge can be retrieved to process the pronouns and tenses learned previously in the sentence [45]. The idea of a close relationship between WM and LTM has been substantiated by a number of research works. Miyake and Shah [46] consider STM as a gateway to LTM. Cowan [47], Gathercole \& Pickering [7], and Kemps, Rammelaere, \& Desmet [48] perceive WM as an activated portion of LTM. Yuan and his associates [43] view LTM and external world as the sources of WM contents. Ericsson \& Kintsch [45] explicates that LTM holds unlimited knowledge and that it overcomes the limitations of WM. In view of its importance, the engagement of LTM should not be overlooked in the design of a WM test.

\section{Proposing Theoretical Framework Of WM As Basis For RESEARCH MATERIALS}

In this study, we adopt the integrated approach by unifying the three major theories discussed above, and term it as "unified theory of WM" (Figure 9). Based on the theory, we designed "objects-span tri-tasks" test and a prototype of tangible multimedia named TangiLearn. 
The International Journal of Multimedia \& Its Applications (IJMA) Vol.8, No.6, December 2016

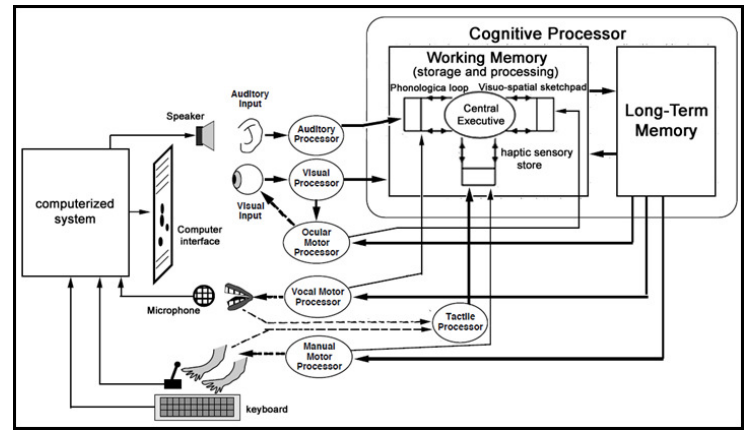

Figure 9. Unified Theory of WM (adapted from [19] [41][42][43])

In the unified theory of WM, we propose an architect of multiple components in WM in a manner similar to that of the subcomponents in BWM's tradition. WM in cognitive processors is fractionated into various partitions catered for different types of information captured by different sense organs. The information input to WM is most effective if it is contributed by three different modalities (visual, auditory and tactile channels) in tandem.

Unifying different models is always an aim of science [48]. It provides a comprehensive picture of WM of a person. It has been a common practice for many researchers in WM, such as Miyake and Shah's [46] synthesised description of multiple dimensional WM, and Oberauer, S"uß, Schulze, Wilhelm, \& Wittmann's [49] hierarchical model of synthesised WM [43].

We draw on ASHM and EPIC because of its postulation on tactile channel, which is relevant to our case study. BWM is included in the unified theory because BWM not only receives wide acceptance in the field of psychology research [5][50][43], but also provides a fitting framework for second language learning [10], which is the investigated domain in the case study. BWM stands as a common model used to understand word learning [52][53] and vocabulary [54].

It is possible to unify ASHM, BWM and EPIC theories because there is a strong correlation between them. They represent a continuum of human memory research works that evolved over the years. BWM and EPIC have its origin from ASHM. ASHM was the first theory that explicitly rationalises the process of human memory in knowledge acquisition. By the early 1970s, ASHM was found too simplistic [46], and incapable of adequately explaining the underlying semantic processing underwent in a learner's mind [56][46], thus Baddeley enhanced ASHM by proposing the term WM to replace the term STS [57]. BWM spurs extremely large number of models that followed [58], including EPIC framework. The three theories unified have much to offer to each other, and to complement each other. As each human memory theory has a certain level of evolution from the past theories, a continuum of the three compelling theories can be illustrated in Figure 10.

\section{EPIC $\longleftarrow$ BWM $\longleftarrow$ ASHM}

Figure 10. Continuum of ASHM, BWM and EPIC Human Memory Theories

This continuum of theories implies that one can select one single theory, combine all theories, or taking the middle of the continuum of theories and apply whenever situation appropriate. 
The International Journal of Multimedia \& Its Applications (IJMA) Vol.8, No.6, December 2016

\section{CaSe Study}

A seven-day case study for testing the WMC of preschoolers after treatment using TangiLearn had been conducted in seven kindergartens. Each lesson lasted one hour per day, for seven days consecutively in each kindergarten.

\subsection{ReSearch Questions of CASE Study}

The study sought to answer the question: Do preschoolers of the TangiLearn system demonstrate an improvement in their learning performance and WMC in English as second lang uage (ESL) learning?

\subsection{ObJective Of The CaSe Study}

The primary objectives of the case study were to first, measure the feasibility and capability of tangible multimedia in supporting ESL learning and WMC of a preschooler. Second, gather feedback regarding the design and procedure for "objects-span tri-tasks" test as well as the improvements required for them.

\subsection{RESEARCH Methodology}

The research framework postulated one independent variable attempted to impose effect on two dependent variables. The independent variable was the multimedia learning system, TangiLearn. This independent variable was expected to show a significant variance on the dependent variables. The dependent variables were learning performance score and WMC. As this case study served as the preliminary step from a series of evaluation plan, we did not include control group for comparison.

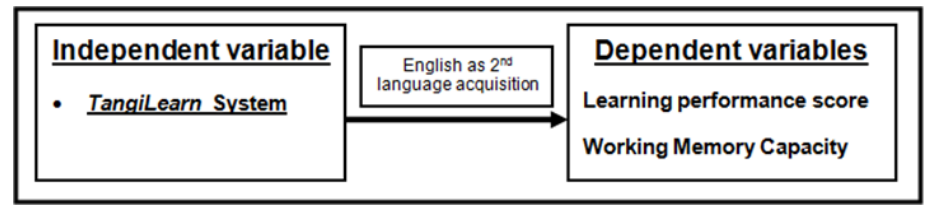

Figure 11. Research Methodology for the Case Study

Albert Shanker Institute [59] defines a quality preschool instruction as an instruction that impose vital and lasting effects on building children's cognitive skills. By setting the learning performance and WMC scores as dependent variable, the real quality of multimedia system can be gauged, that is whether the TangiLearn was able to maximise learning performance and yet can lessen the amount of WM load of a preschooler at the same time.

We deployed quizzes (pre and post-quiz) and "objects-span tri-tasks" test as metrics for measuring the preschoolers' learning performance and WMC respectively (Figure 12). Both prequiz and post-quiz were composed of 12 questions. Pre-quiz was a measure of the prior knowledge of preschoolers on contents to be learned. It was held 7 days prior to the conduct of the study to obtain a baseline performance for comparison with results from the post-quiz. The aim of post-quiz was to assess the preschoolers' knowledge gained after the system treatment. The pre-quiz and post-quiz were similar in some contents, but were arranged in a randomised order to avoid the "set response effect". Some were modified but the contents remained the same. 
Apart from that, unstructured observations and interviews, which offer us key insights into issues not obviously attested in quantitative results, were further utilised to collect feedback from participants.

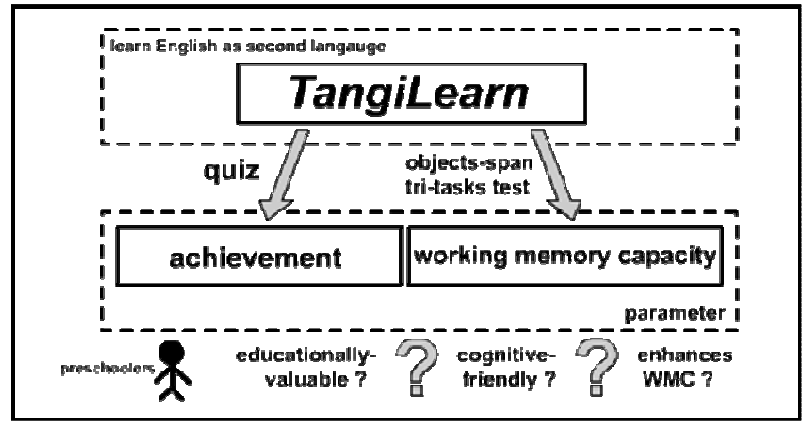

Figure 12. Case Study Research Design

\subsection{The Participants}

248 preschoolers (121 males and 127 females) age five and six from seven Malaysian kindergartens were selected as the participants in the case study. The participants chosen were homogeneous in terms of age, prior knowledge, and English level. They did not speak, or rarely spoke English at home. The participants must not have attended any lesson on the topics covered by the treatment system, for us to attribute their knowledge to the efficacy of the system they used. The decision to select five and six year old children was justified by the fact that this is the time when most Malaysian children officially start learning ESL in kindergartens [60]. In addition, they are categorised as children in the stage of "pre-operation" cognitive development. Preschoolers took part in this study voluntarily. They were not told about the nature of the study. However, they were told that they could stop learning Tangilearn at any time.

\subsection{The DeSign OF “OBJECTS-SPAN Tri-TASKs” TeST}

"Objects-span tri-tasks" test is a memory tasks test designed to measure the WMC of a preschooler undergone treatment using TangiLearn. The basic idea of the test is the simultaneous reproduction of the words and sequence of the words learned in the TangiLearn. Such reproduction translates dual-functionality of WM, simultaneous storage and processing of information into testing instrument. The preschoolers' WMC is the size of the largest sequence of correctly spelled words able to be recalled by the preschoolers.

During the case study, the "objects-span tri-tasks" test started when a preschooler was sequentially presented with 3 words with which each was printed on different cards. 3 letters in each word were left blank.

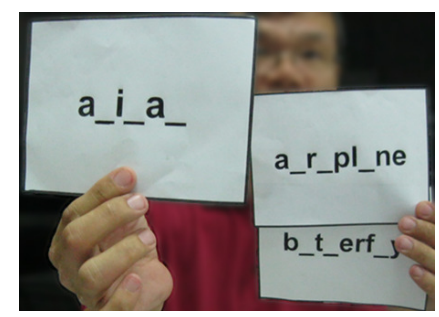

Figure 13. Three Letters Left Blank in Words in "Objects-Span Tri-Tasks" Test 
Each word would be remained for viewing for 15 seconds, followed by a one-second interstimulus-interval (ISI). We started from 3 words because the past research shows that 4 to 6 years old children could repeat sequences of digits from 3 to 4 digits [61]. After the presentation of the words, the preschooler was requested to write down the words in full and in the right order on answer sheet.

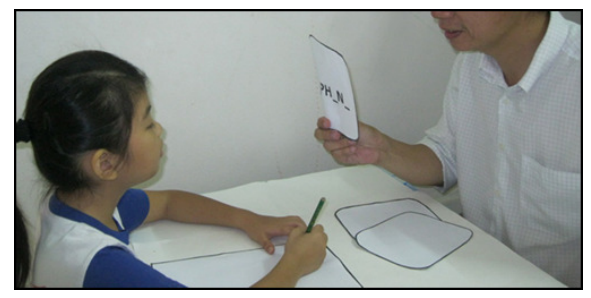

Figure 14. The "Objects-span Tri-tasks" test

As observed, the preschoolers were to perform three tasks in this test. A triple task paradigm is a logical extension of dual task performance [62]. Triple tasks performance investigated by McColskey [62], Stager \& Laabs [63], and Wickens [64], though in different domain, demonstrate the possibility of carrying out triple tasks paradigm in a WM testing instrument. The first task in "objects-span tri-tasks", recall the words presented, suggests the use of short-term storage function of WM because information storage is measured through forgetting [56][57]. The second task, recall the order of the sequence of words, implicates the processing function of WM. Although tasks requiring sequence recall is not always necessary for cognition operation, it is crucial for many acts of higher order cognition such as language acquisition and navigating routes which require memorising a series of turns and locations [65][66]. This is because memorising a sequential order of events entails strategy uses and efforts [67][65]. The third task, recall the 3 letters left blank in a word, was alluded to the engagement of LTM.

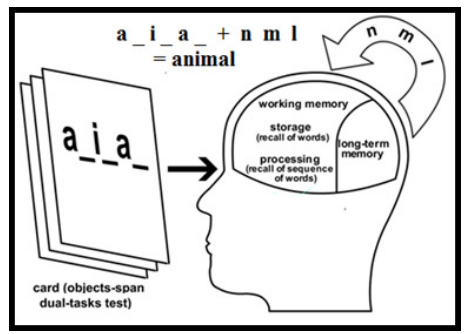

Figure 15. Three Tasks in Human Cognition Triggered Using the "Objects-Span Tri-Tasks" Test

The presentation time for viewing was limited, but the time for writing the answer was not. This was because firstly, the mastery of vocabulary was limited among preschoolers. Secondly, flexibility in writing time would help to reduce stress that may occur among the preschoolers. If the words, their sequence, and missing letters were recalled correctly, the preschooler would proceed to next level. The sequence length of the words would be progressively increased by one in each subsequent level. The test would be discontinued if the preschooler has committed three full consecutive incorrect words, sequences or missing letter recalls. Two levels of test would be conducted as practice trials. The total administration time required was between 15 and 20 minutes for each participant, including practice trial. Three types of scores, namely, the score for correctly arranged sequence of words, the score for words correctly recalled, and the score for missing letters recalled, would be obtained. Each correct recall would be awarded 1 mark. Preschoolers' total score on these three tasks were the measures of their WMC. This way of calculating had the advantage of obtaining individual scores from single items. 
The International Journal of Multimedia \& Its Applications (IJMA) Vol.8, No.6, December 2016

The tasks in "objects-span tri-tasks" was set by reference to the "backward digit" [68][49], "backward word" [69][43], "mathematics-span dual-tasks", and "reading-span dual-tasks" [70] span test. The difference of these instruments lies in the contents of the task and the way the task is processed. For "backward digit" and "backward word" span test, the processing task is the recitation of the order of the numbers and words respectively. The processing task in "mathematics-span dual-tasks" is to choose two numbers with which the total could be divided by three and "reading-span dual-tasks" is to read aloud a set of sentences apart from the recitation of the last word in the sentences as the memory task. Besides contents, another difference between "objects-span tri-tasks" test and these tests is the overt setting of tasks that reflects the engagement of LTM in supporting the operation of WM (Figure 15).

Dual-tasks have become a standard for measuring WM. A memory test that invokes dual-tasks is not only a valid measure of WM [71][43][72][73][49], but also a good predictor for higher order cognitive skills [74]. Simple memory tests such as "backward digit" and "backward word" span tests are not a good measurement for WM [74][2] because they merely require the participants to conserve information given. Direct conservation of information only taps the storage functionality of WM [47].

\subsection{THE IMPLEMENTATION OF THE TANGILEARN}

Sensor technology which comprises RFID readers, spatial sensors, touch sensors, and electronic sliders was deployed interchangeably to implement the tactile attribute in multimedia.

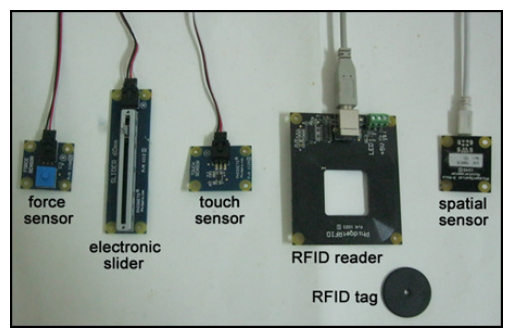

Figure 16. Sensor Devices Deployed in Tangilearn

The setting of TangiLearn was done in a way that an array of tangible objects was arranged on the display table in front of computer. Adopting the approach of self-explorative learning in the Constructivist theories, participants were requested to identify, pick, and play around freely with any tangible object to trigger the corresponding virtual learning contents in animations and videos on the computer screen when the study started for 30 minutes. The full learning sessions were concluded with a post-quiz and an "objects-span tri-tasks" test.

The learning contents of TangiLearn system were designed to focus on the learning of real-life objects in ESL, compliant with the National Preschool Curriculum (NPC) of Malaysia. NPC emphasises the mastery of language skills for preschoolers [75]. Topics of real-life objects were limited to animals, fruits, and stationery. Mastering the name and relevant key terms of the objects was the main objective of TangiLearn. Animals and fruits were chosen in this case study because the study of animals and plantations are subjects learned in the lowest grades in kindergartens [76]. Stationery was chosen because there have been views that items (school bus, school items etc.) within a 15-minute walk from the children's school can be an important source for teachers in selecting subjects for learning [77]. Bruner [78] further elaborates that the more basic the idea the students have learned, the greater their ability in applying it to new problems [79]. In view of this, the three topics chosen were highly suitable for the study. No abstract 
materials or concepts like "melt", "minus", "think" or grammar of the language were introduced, consistent with the level of cognitive development of young children [15].

To identify tangible objects, the TangiLearn system was designed in a way that RFID tag was inserted into tangible object (Figure 17). By moving the tangible object towards a compatible RFID reader, the tag would transmit relevant information to the reader, and thereby triggered mutual communication between multimedia expressions and tangible objects for learning.

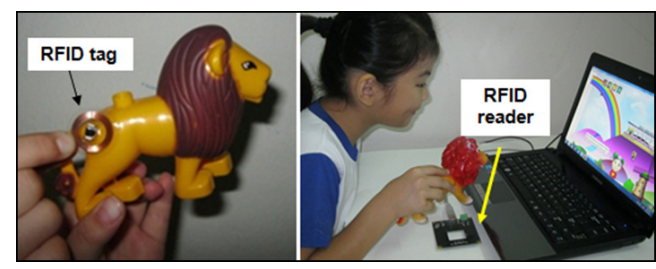

Figure 17. Implementation of RFID Technology

In fruits learning session where tangible apple was attached on the handle of an electronic slider. The electronic slider, a linear potentiometer with its sensor value varied linearly with the position of the slider, was used as position feedback for the position of the tangible apple. By grasping and moving the slider embedded tangible apple from left to right, the virtual apple would be moved accordingly (Figure 18), and this triggered a sense of spatiality in the mind of preschoolers. Based on the unified theory of WM, this way of learning was believed to be more comprehensive than plain pictures, because an image of an apple, though recognisable, has no substantial spatial organisation [80].
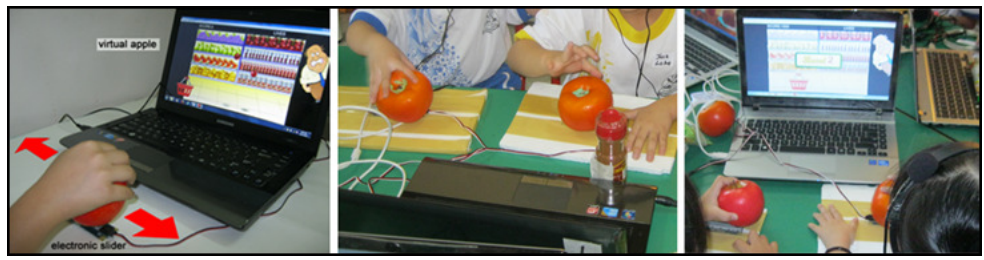

Figure 18. Electronic Slider Attached on Tangible Apple in Apple Catching Game

In cooking and sewing learning sessions, we set the mastery of the name of the tangible objects involved, when and how they were used as the main learning outcomes. For instance, when "add sauce" text was shown on computer screen (Figure 19a), the preschooler would be requested to grab the RFID embedded tangible sauce. If the preschooler grabbed the object correctly, the virtual sauce would be slowly moved towards the virtual wok (Figure 19b). Otherwise, an error notification would be displayed.

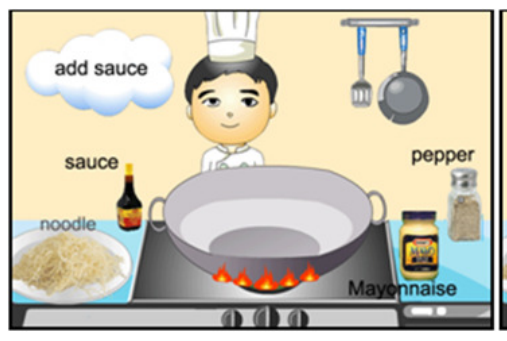

Figure 19a. Cooking Session

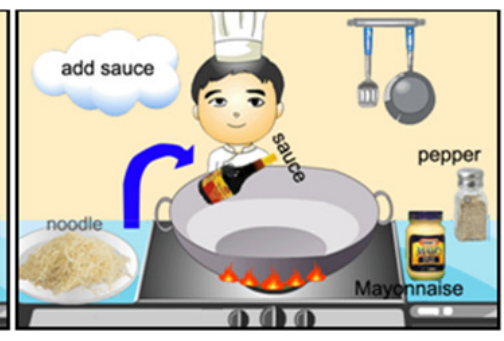

Figure 19b. Moving Virtual Sauce 
The subsequent step for the preschooler was to experience spatial activity using spatula. After all "ingredients" were "poured" into the virtual wok, a virtual spatula would be shown (Figure 20a). This implied that the preschooler needed to pick the spatial sensor embedded tangible spatula, and performed gestural movement to trigger a simulation of the stirring action.

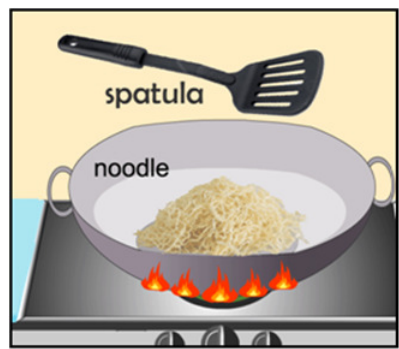

Figure 20a. Moving Spatula

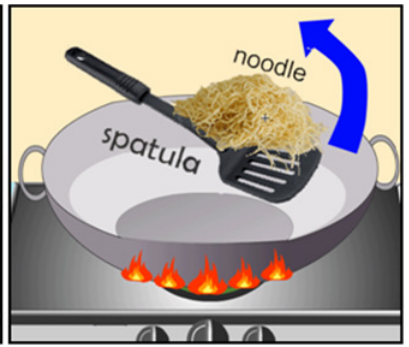

Figure 20b. Stirring Spatula

\subsection{THE FINDINGS}

The post-quiz results show that the participants successfully learned the contents associated with tangible objects from the system. Out of 12 questions, 82 participants obtained more than $75 \%$ of marks (distinction) in post-quiz after treatment using TangiLearn.

Table 1. Participants' Performance in Quizzes.

\begin{tabular}{|l|c|c|c|c|}
\hline Type of quiz & Fail & Pass & Merit & Distinction \\
\hline Pre-quiz & 52 & 141 & 55 & 0 \\
\hline Post-quiz & 18 & 36 & 112 & 82 \\
\hline
\end{tabular}

From the WMC test, the preschoolers gained a mean score of 5.83 in Task 1, 4.17 in Task 2, and 3.67 in Task 3. None of the participants was able to advance beyond the fourth level (Table 2).

Table 2. Participants' WM Score in “Objects-span Tri-tasks” Test.

\begin{tabular}{|c|c|c|c|}
\hline Subjects & $\begin{array}{c}\text { Task l mean } \\
\text { (Number of correctly } \\
\text { arranged sequence) }\end{array}$ & $\begin{array}{c}\text { Task 2 mean } \\
\text { (Number of words } \\
\text { recited) }\end{array}$ & $\begin{array}{c}\text { Task 3 mean } \\
\text { (Number of missing } \\
\text { letters recited) }\end{array}$ \\
\hline 248 & 5.83 & 4.17 & 3.67 \\
\hline
\end{tabular}

Due to the lack of research works in the adoption of tangibility in multimedia, we are unable to examine any existing mean of score as a baseline measurement of the preschooler's WMC for reference. To gauge the status of our findings in WMC, we referred mean of scores in some of the well-established WM test, though the way they conducted the WM was different. Compared with the mean score of backward digit span (4.87), reading span (3.70), math span (5.39), verbal span (3.63) and computation span (5.25) in the past research works [49], the "objects-span tri-tasks" results provided an idea of the performance of WMC of TangiLearn participants.

The satisfactory performance of quiz and memory tests was believed to be attributed to the physical sensation of tangible objects. We noticed that the participants were highly motivated by TangiLearn. Their emotional and facial expressions indicated that they explored the system excitedly. They liked holding and tinkering with the tangible objects augmented with sensors. When we asked what they liked most about the system, majority of them answered that what they liked most was the part where tangible objects, particularly toy-like objects, were bound up with digital multimedia expressions. They seemed to be tricked into the belief that the digital 
The International Journal of Multimedia \& Its Applications (IJMA) Vol.8, No.6, December 2016

multimedia objects had been made "graspable" for them. To them, TangiLearn was "technologically" simple (allowed them to understand the tasks easily) and novel (they have not seen such tangible system before).

Unlike majority of the commercial multimedia systems in market that deliver rote contexts, such as where their screens are filled with menus and buttons written with school terminologies (exercises, examples, and vocabulary), the meaningful context augmented with authentic tangible objects in TangiLearn delivered knowledge that was associated with learners' prior knowledge. For example, in animals learning session, the National Zoo in Kuala Lumpur was set as background. In zoo, the learners have already known some animals, and from what they already knew, TangiLearn system introduced more new animals. With the connection to known animals, new animals were learned easier and faster. Children learn best when learning materials are presented in meaningful contexts [59][83]. Tangible objects themselves are real-world concrete materials. The strength of its physical affordances allowed the situation of "decontextualised" learning [84] to be avoided. If knowledge taught is separated from how and what the young children see in real life, unnecessary cognitive load will be incurred as they will wonder whether such things exist in the reality. According to Alessi and Trollip [82], a heavy cognitive load will have adverse effects on learners' motivation and transfer of learning [76].

The case study also observed flaws in the WM test and some refinements were required. During the course of the "objects-span tri-tasks" test, it was found that all participants were unable to advance beyond the fourth level. We suspect that the starting sequence length and number of missing letters in the test were set beyond the capability of preschoolers in Malaysia, despite past surveys in other countries that confirmed the setting to be appropriate [61]. To ensure accuracy of research outcomes, memory span tests should start with an easy load of information which the preschoolers must repeat [81], thus we are considering to alter the viewing time for each sequence of words from 15 to 30 seconds. By giving a longer time for viewing, it is expected that the WMC of the participants can be more accurately reflected. The second alteration is on the number of topics covered. It was found that the scope of topics covered was broad for the young participants to cope with. The third is the reduction of the syllable of each word recalled. This is because lengthy syllables may demand the involvement of other components of WM. Fourth, some of the preschoolers had problems in writing due to their limited vocabulary mastery. Therefore, instead of asking them to write the answer on the answer sheet, using answer options printed on cards for the young participants to point to is more plausible. Fifth, observation revealed that the preschoolers are capable of handling many tests, as such, we plan to conduct "objects-span tritasks" twice, that is, before and after treatment. Lastly, there was a suggestion from a teacher that tangible objects should be used instead of text printed on cards for viewing during the WM test. This suggestion is of valuable for consideration in view that it could more accurately reflect the aim of study.

\section{CONCLUSION}

This case study is an attempt to examine the potential of tangible multimedia to orient preschoolers toward ESL learning that will be much different from the past multimedia. The findings reveal that TangiLearn, which was designed in and based on unified theories of WM, appears to have positively impacted children's ESL acquisition and WMC. A conclusion that can be drawn from the findings is that multimedia that was translated from the unified theories of WM helps establish not only the intuitiveness elements in digital multimedia learning for preschoolers, but also a means for upholding a preschooler's WMC.

We believe this paper moves beyond many of the research questions commonly done in multimedia realm in four aspects. First, this paper sheds light on the fact that multimedia research in terms of the aspect of WM of learners, which is understudied, is an area that can be further 
The International Journal of Multimedia \& Its Applications (IJMA) Vol.8, No.6, December 2016

researched. "Objects-span tri-tasks" memory test, which closely mirrors the dual-tasks methodology, has been designed for measuring the WM of preschoolers in multimedia learning. Secondly, this paper attempts to unify the three compelling WM theories (BWM, ASHM, and EPIC framework). Our study shows that their dimensions could interact to produce some insights into WM in the multimedia context. We argue that our tangible multimedia system and WM test have strong theoretical base because they are designed based on the unified theory of WM, the tripartite theory formulated from the three aforesaid theories. Thirdly, this paper demonstrates an important step forward in multimedia research by proposing a genre of multimedia that manifests the tactile attribute for learning. Despite some inherent drawbacks in the procedure of the case study, the preliminary findings are of considerable value, and have practical implications on the use of the system. Finally, our study illustrates a cross-disciplinary investigation across three distinct domains, from computing domain (multimedia), cognitive psychology (WM) to applied linguistics (ESL). The success of such a study will add value to the innovative approach design in multimedia settings.

On the whole, the findings of this case study have provided initial views that TangiLearn is educationally valuable and cognitive-friendly to preschoolers. Tangible multimedia and WM test are in the initial stage of research, and their designs are still in the beta version. We hope to encourage and invite more relevant research to substantiate or repudiate the preliminary conclusions drawn in this study.

\section{REFERENCES}

[1] Abbott, E. N. (2007). Comparative study of the working memory scales of the WISC-IV and SB5 in referred students. Unpublished Bachelor Dissertation. Marshall University. Retrieved from http://www.marshall.edu/etd/masters/abbott-erica-2007-ma.pdf

[2] Abu-Rabia, S. (2003). The Influence of working memory on reading and creative writing processes in a second language. Educational Psychology, 23, pp209-222.

[3] Daneman, M., \& Tardif, T. (1987). Working memory and reading skill re-examined. In M. Coltheart (Ed.), Attention and performance, 7, pp491-508. London: Erlbaum.

[4] De Smedt, B., Ghesquiere, P., \& Verschaffel, L. (2004). Working memory and arithmetic abilities in seven and eleven year old children. The European Working Memory Symposium (EQOMS II), Beaune, France.

[5] Gathercole, S. E., Pickering, S. J., Knight, C., \& Stegmann, Z. (2004). Working memory skills and educational attainment: Evidence from national curriculum assessments at 7 and 14 years of age. Applied Cognitive Psychology, 18, pp1-16. DOI: 10.1002/acp.934

[6] Alloway, T. P. (2006). How does working memory work in the classroom. Educational Research Review, 1, pp134-139.

[7] Gathercole, S. E., \& Pickering, S. J. (2000) Working memory deficits in children with low achievements in the national curriculum at seven years of age. British Journal of Educational Psychology, 70, pp177-194. Britain: The British Psychological Society.

[8] Cain, K., Oakhill, J., \& Bryant, P. (2004). Children's reading comprehension ability: Concurrent prediction by working memory, verbal ability, and component skills. Journal of Educational Psychology, 96(1), pp31- 42.

[9] Oberauer, K. (2005). Binding and inhibition in working memory: Individual and age differences in short-term recognition. Journal of Experimental Psychology: General, 134(3), pp368 - 387.

[10] Londe, Z. C. (2008). Working memory and English as a second language listening comprehension test: A latent variable approach. PhD. dissertation. University of California, Los Angeles.

[11] Service, E. (1992). Phonology, working memory, and foreign-language learning. Quarterly Journal of Experimental Psychology, 45A, pp21-50.

[12] Torres-Fernandez, D.I. (2008). Gender differences in working memory and phonological awareness. $\mathrm{PhD}$. dissertation, Capella University, Minnesota.

[13] Pant, A. (2006). Multimedia effects on memory: Exploring the visual channel load explanation for the redundancy effect. PhD. Dissertation. School of Business, University of Kansas. 
The International Journal of Multimedia \& Its Applications (IJMA) Vol.8, No.6, December 2016

[14] Schwartz, N.C. (2005). Integral or irrelevant? The impact of animation and sound effects on attention and memory for multimedia messages. PhD. dissertation. Department of Instructional Systems Technology, Indiana University

[15] Piaget, J. (1952). The origins of intelligence in children. New York: University Press.

[16] Piaget, J. (1972). The principles of genetic epistemology. New York: Basic Books.

[17] Barnes, S. K. (2010). Using Computer-Based Testing with Young Children. PhD. dissertation. James Madison University.

[18] Chooi, W. T. (2011). Improving intelligence by increasing working memory capacity. PhD. Dissertation. Case Western Reserve University.

[19] Atkinson, R. L., \& Shiffrin, R. M. (1968). Human memory: A proposed system and its control processes. In K. W. Spence \& J. T. Spence (Eds.) The psychology of learning and motivation: Advances in research and theory, 2, pp89-195. New York: Academic.

[20] Kieras, D. E., \& Meyer, D. E. (1997). An overview of the EPIC architecture for cognition and performance with application to human-computer interaction. Human-Computer Interaction, 12, pp391-438. Lawrence Erlbaum Associates.

[21] Ullmer, B., \& Ishii, H. (2001). Emerging Frameworks for Tangible User Interfaces. In Carroll, J. M. (Ed.), Human-Computer Interaction in the New Millenium, pp579-601. USA: Addison-Wesley.

[22] Klemmer, S. R., Hartmann, B., \& Takayama, L. (2006). How bodies matter: Five themes for Interaction Design. Proceedings from DIS '06: The 6th Conference on Designing Interactive Systems, pp140-149.

[23] Morsella, E. \& Krauss, R. M. (2004). The role of gestures in spatial working memory and speech. American Journal of Psychology, 117(3), pp411- 424.

[24] Papert, S. (1991). Situating constructionism. In Papert \& Harel (Eds.), Constructionism. Cambridge, MA: MIT Press.

[25] Zuckerman, O, \& Resnick M. (2003). System blocks: A physical interface for system dynamics learning. Proceedings of the 21st International System Dynamics Conference, pp810-811. USA: ACM Press.

[26] Manches, A. (2010). The effect of physical manipulation on children's numerical strategies: Evaluating the potential for tangible technology. Unpublished doctoral dissertation. University of Nottingham, UK.

[27] Burnett, A. (1962). Montessori education today and yesterday. The Elementary School Journal, 63, pp71-77.

[28] Marco, J., Cerezo, E., Baldassarri, S. Mazzone, E., \& Read, J.C. (2009). Bringing tabletop technologies to kindergarten children. HCI 2009 - People and Computers XXIII, 103-111. UK: British Computer Society. p. 105

[29] Antle, A. N., Droumeva, M., \& Ha, D. (2009). Hands on what? Comparing children's mouse-based and tangible-based Interaction. Proceedings from IDC '09: The 8th International Conference on Interaction Design and Children, pp80-88.

[30] Manches, A., O'Malley, C., \& Benford, S. (2009). Physical manipulation: Evaluating the potential for tangible designs. Proceedings from TEI "09: The 3rd International Conference on Tangible and Embedded Interaction, pp77-84.

[31] Soro, A., Deriu, M., \& Paddeu, G. (2009). Natural exploration of multimedia contents. Proceedings of MoMM2009: The 7th International Conference on Advances in Mobile Computing and Multimedia, pp382-385.

[32] Sweller, J. (1994). Cognitive load theory, learning difficulty and instructional design. Learning and Instruction, 4, pp295-312.

[33] Paivio, A. (1986). Mental representation: A dual-coding approach. New York: Oxford University Press.

[34] Oh, E. (2010). Validating a theory-based model of L2 reading comprehension: Relative contributions of content-specific schematic knowledge and L2 vocabulary knowledge to comprehending a science text. Ph.D., Dissertation. University of Maryland.

[35] Nahrstedt, K. \& Steinmetz R. (2002). Multimedia fundamentals volume 1: media coding and content processing. US: Prentice Hall.

[36] Xie, Z. (2008). Comparing children's enjoyment and engagement using physical, graphical and tangible user interfaces. Master dissertation. School of Interactive Arts and Technology, Simon Fraser University, Canada. 
The International Journal of Multimedia \& Its Applications (IJMA) Vol.8, No.6, December 2016

[37] Ishii, H. \& Ullmer, B. (1997). Tangible bits: Towards seamless interfaces between people, bits and atoms. Proceedings from CHI'97: The SIGCHI Conference on Human Factors in Computing Systems, pp234-241.

[38] Dourish, P. (2001). Where the Action Is: The Foundations of Embodied Interaction. USA: MIT Press.

[39] Marshall, P., Price, S., \& Rogers, Y. (2003). Conceptualising tangibles to support learning. Interaction Design and Children, pp101-109.

[40] Brown, J. (1958). Some tests of the decay theory of immediate memory. Quarterly Journal of Experimental Psychology, 10, pp12-21.

[41] Atkinson, R. L., \& Shiffrin, R. M. (1971). The control of short-term memory. Scientific America, 225, pp82-90.

[42] Kieras, D. E., Meyer, D. E., Mueller, S., \& Seymour, T. (1999). Insights into working memory from the perspective of the EPIC architecture for modeling skilled perceptual-motor and cognitive human performance. In A. Miyake, \& P. Shah (Eds.), Models of working memory: Mechanisms of active maintenance and executive control, pp183-223. New York: Cambridge University Press.

[43] Yuan, K., Steedle, J., Shavelson, R., Alonzo, A., \& Oppezzo, M. (2006). Working memory, fluid intelligence, and science learning. Educational Research Review 1, pp83-98. Elsevier Ltd. doi:10.1016/j.edurev.2006.08.005

[44] Metiri Group. (2008). Multimodal learning through media: What the research says. Cisco White Paper. San Jose, CA: Cisco Public Information. Retrieved from http://www.cisco.com/web/strategy/docs/education/Multimodal-Learning-Through-Media.pdf

[45] Ericsson, K. A., \& Kintsch, W. (1995). Long-term working memory. Psychological Review, 102(2), 211-245. doi: 10.1037/0033-295X.102.2.211

[46] Miyake, A., \& Shah, P. (1999). Models of working memory: Mechanisms of active maintenance and executive control. Cambridge University Press. Retrieved from http://psychwww.colorado.edu/ miyake/MWM\%20Chapter\%201.pdf

[47] Cowan, N. (2001). The magical number 4 in short-term memory: a reconsideration of mental storage. Behavioral and Brain Sciences, 24(1), pp87-185.

[48] Kemps, E., Rammelaere, S. D., \& Desmet, T. (2000). The development of working memory: Exploring the complementarity of two models. Journal of Experimental Child Psychology, 77, 89109. doi:10.1006/jecp.2000.2589

[49] Oberauer, K., S“uß, H.-M., Schulze, R., Wilhelm, O., \& Wittmann, W.W. (2000). Working memory capacity - facets of a cognitive ability construct. Personality and Individual Differences, 29, 10171045. Retrieved from http://eis.bris.ac.uk/ psxko/Oberauer.et-al.2000.PAID.pdf

[50] Sweller, J., van Merrienboer, J. J. G., \& Paas, F. G. W. C. (1998). Cognitive Architecture and Instructional Design. Educational Psychology Review, 10(3), pp251-296. Plenum Publishing Corporation.

[52] Gathercole, S.E., Hitch, G.J., Service, E., \& Martin, A.J. (1997). Phonological short-term memory and new word learning in children. Developmental Psychology, 33(6), pp966-979.

[53] Weill, F. (2011). The role of verbal working memory in new word learning in toddlers 24 to 30 months old. PhD. dissertation. Seton Hall University.

[54] Gathercole, S.E., \& Adams, A.M. (1994). Children's phonological working memory: Contributions of long-term knowledge and rehearsal. Journal of Memory and Language, 33, pp672-688.

[56] Baddeley, A. D. (2004). Chapter 1: The psychology of memory. In A.D. Baddeley, M.D. Kopelman, \& B.A. Wilson (Eds.). The Essential Handbook of Memory Disorders for Clinicians. USA: John Wiley \& Sons.

[57] Baddeley, A., \& Hitch, G. J. (1974). Working memory. In G. H. Bower (Ed.), The Psychology of Learning and Motivation, 8, 47-89. New York: Academic Press.

[58] Olive, T. (2004). Working memory in writing: Empirical evidence from the dual-task technique. European Psychologist, 9(1), pp32-42. Retrieved from http://cogprints.org/3246/1/Olive_Euro_Psy.pdf

[59] Albert Shanker Institute. (2009). Preschool curriculum: What's in it for children and teachers. USA. Retrieved from http://www.shankerinstitute.org/Downloads/Early\%20Childhood\%2012-11-08.pdf

[60] Mohamad Jafre Zainol Abidin, Majid Pour-Mohammadi, Souriyavongsa, T., Chin Da, \& Ong, L. K. (2011). Improving Listening Comprehension among Malay Preschool Children Using Digital Stories. International Journal of Humanities and Social Science, 1(14), pp159-164.

[61] Szmalec, A., Brysbaert, M., \& Duyck, W. (2012). Working memory and (second) language processing. In J. Altarriba \& L. Isurin (Eds.). Memory and Language: Theoretical and Applied 
The International Journal of Multimedia \& Its Applications (IJMA) Vol.8, No.6, December 2016

Approaches to Bilingualism. Boston, MA:Walter De Gruyter. Retrieved from http://crr.ugent.be/papers/Szmalec\%20et\%20al\%20Working\%20Memory\%20and\%20Second\%20Lan guage\%20Processing.pdf

[62] McColskey, A. M. (1982). The influence of hemispheric load on performance and learning in a dual/triple task paradigm. PhD. Dissertation. College of Education, The Florida State University.

[63] Stager, P., \& Laabs, G.J. (1977). The effect of divided attention on probe reaction time in multipletask performance. Canadian Journal of Psychology, 31, pp174-183. The third task, the recall of 3 missing letters in each word, suggests the engagement of LTM.

[64] Wickens, C. (1976). The effects of divided attention of information processing in manual tracking. Journal of Experimental Psychology: Human Perception and Performance, 2, pp1-13.

[65] Rowe, G. (2010). Determinants of working memory performance. PhD. dissertation. Department of Psychology, University of Toronto, Canada

[66] Burgess, N., \& Hitch. G. J. (1999). Memory for Serial Order: A Network Model of the Phonological Loop and its Timing. Psychological Review, 106, pp551-581.

[67] Moscovitch, M., \& Winocur, G. (1992). The neuropsychology of memory and aging. In F. I. M. Craik \& T. A. Salthouse (Eds.), The handbook of aging and cognition. pp315-371. Hillsdale, NJ: Lawrence Erlbaum Associates, Inc.

[68] Ackerman, P. L., Beier, M. E., \& Boyle, M. O. (2002). Individual differences in working memory within a nomological network of cognitive and perceptual speed abilities. Journal of Experimental Psychology: General, 131, pp567-589.

[69] Rosen, V. M., \& Engle, R. W. (1997). Forward and backward serial recall. Intelligence, 25, pp37-47.

[70] Fedorenko, E., Gibson, E., \& Rohde, D. (2007). The nature of working memory in linguistic, arithmetic and spatial integration processes. Journal of Memory and Language, 56, pp246-269. Retrieved from http://tedlab.mit.edu/tedlab_website/researchpapers/Fedorenko_et_al_2007_JML.pdf

[71] Kyllonen, P. C. (2002). g: Knowledge, speed, strategies, or working memory capacity? A systems perspective. In R. J. Sternberg, \& E. L. Gigorenko (Eds.), The general factor of intelligence: How general is it?, pp415-445. Mahwah, NJ: Erlbaum.

[72] Derrfuss, J., Brass, M., \& von Cramon, D. Y. (2004). Cognitive control in the posterior frontal cortex: evidence from common activations in task coordination, interference control, and working memory. Neuroimage, 23, pp604-612.

[73] Grabner, R. H., Fink, A., Stipacek, C., Neuper, A. C., \& Neubauer, A. C. (2004). Intelligence and working memory systems: evidence of neural efficiency in alpha band ERD. Cognitive Brain Research, 20, pp212-225.

[74] Daneman, M., \& Carpenter, P. A. (1980). Individual differences in working memory and reading. Journal of Verbal Learning and Verbal Behavior, 19, pp450-466.

[75] Challenger Concept. (2009). Schools of Malaysia directory: Your guide to children's schooling and upbringing. Selangor: Challenger Concept (M) Sdn Bhd.

[76] Haury, D. L. \& Rillero, P. (1994). How does or should the use of hands-on materials vary with age? Perspectives of Hands-On Science Teaching. North Central Regional Educational Laboratory. Retrieved from http://www.ncrel.org/sdrs/areas/issues/content/cntareas/science/eric/eric-8.htm

[77] Tredway, D. (1982). The local environment: A learning experience. Science and Children, 20(1), pp16-17.

[78] Bruner, J. S. (1968), Toward a Theory of Instruction. New York: Norton.

[79] Cooperstein, S. E., \& Kocevar-Weidinger, E. (2004). Beyond active learning: A constructivist approach to learning. Reference Services Review, 32(2), pp141-148. DOI $10.1108 / 00907320410537658$

[80] Piaget, J. (1968). The construction of reality in the child. London: Routledge \& Kegan Paul Ltd.

[81] Laumann, L.L. (1999). Adult age differences in vocabulary acquisition as a function of individual differences in working memory and prior knowledge. PhD. dissertation. The Eberly College of Arts and Sciences, West Virginia University.

[82] Alessi, S. M., \& Trollip, S. R. (2001). Multimedia for learning: Methods and development (3rd Edition). Boston: Allyn and Bacon.

[83] Maddux, C. D., Johnson, D. L., Willis, \& J. W. (2001). Educational computing: Learning with tomorrow's technologies. USA: Allyn and Bacon.

[84] Chen, C. J. (2005). The design, development and evaluation of a virtual reality (VR)-based learning environment: Its efficacy in novice car driver instruction. Unpublished doctoral dissertation. Universiti Sains Malaysia, Penang. 
The International Journal of Multimedia \& Its Applications (IJMA) Vol.8, No.6, December 2016

\section{AUTHORS}

Zarina Samsudin is an Associate Professor of Centre for Instructional Technology and Multimedia (CITM) in Universiti Sains Malaysia (USM). She obtained her Doctor of Education (Ed.D) i n Computers in Education from University of Minnesota, U.S.A. Her research interests are in the area of instructional technology, issues and copyright in multimedia, and multimedia project management.

Wan Ahmad Jaafar Wan Yahaya is an Associate Professor and Director of CITM, USM. He holds a Ph.D. degree in Educational Multimedia from the University of Leeds, UK and M.Ed in Computer in Education from the University of Manchester, UK. Currently, he is teaching graduate and und ergraduate students in Instructional Multimedia and Persuasive Technology. Dr. Jaafar is a consultant of several projects in the multinational companies as

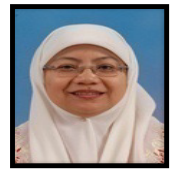
well as many private colleges. He is also involved in the study of ICT initiatives in Malaysian schools as well as in Cambodia. His project entitled "Managing Children Dental Anxiety Through Digital Persuader" won the gold award and special award in the Malaysia Technology Expo (MTE 2012). Another project entitled "Persuasive Multimedia Learning Environment (PMLE)" also won the Gold Award in the 20th International Invention, Innovation, Industrial Design \& Technology Exhibition 2009 (ITEX09) competition. He also won a bronze medal in Seoul International Invention Fair (SIIF) 2010 and in the 23rd 20th International Invention, Innovation, Industrial Design \& Technology Exhibition 2012 (ITEX12) competition. He is currently applying for patent to commercialise the product.

Chau Kien Tsong is an assistant professor of Faculty of Art and Design in Southern University College. He obtained his Ph.D. in multimedia from USM. His research interests are in the area of multimedia and 3D animation.

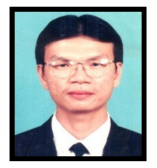

